\title{
Eyelid Tremor in a Patient with Anti-Caspr2 Antibody-Related Encephalitis
}

\author{
Shuichi Ueno ${ }^{a, b} \quad$ Makito Hirano $^{a, b}$ Hikaru Sakamoto $^{a}$ \\ Susumu Kusunoki ${ }^{b}$ Yusaku Nakamura ${ }^{a}$ \\ ${ }^{a}$ Department of Neurology, Sakai Hospital, and ${ }^{b}$ Department of Neurology, Kinki \\ University Faculty of Medicine, Osaka, Japan
}

\section{Key Words}

Eyelid tremor · Blepharoclonus · Anti-Caspr2 antibody-related encephalitis

\begin{abstract}
We describe the first case of a patient with eyelid tremor probably associated with anticontactin-associated protein-like 2 (Caspr2) antibody. Encephalitis associated with antivoltage-gated potassium channel antibody is now attributed to autoantibodies against leucine-rich glioma inactivated 1 (Lgi1) and less frequently against Caspr2. Eyelid tremor or blepharoclonus is a rare or underdiagnosed involuntary movement that has been found in patients with infarction in the thalamus or drug-induced or idiopathic parkinsonism. Since patients with anti-Caspr2 antibody-related encephalitis occasionally have extrapyramidal signs, we speculate that the eyelid tremor was also caused by anti-Caspr2 antibody in our patient. Partial resolution of his symptoms by plasmapheresis also supported the involvement in immunological processes.

(C) 2014 S. Karger AG, Basel
\end{abstract}

\section{Introduction}

Eyelid tremor or blepharoclonus is a rare or underdiagnosed involuntary movement that has been found in patients with infarction in the thalamus or drug-induced or idiopathic parkinsonism [1], suggesting dysfunction of the basal ganglia. Anti-voltage-gated potassium channel antibody-associated encephalitis is now attributed to autoantibodies against leucine-rich glioma inactivated 1 (Lgi1) and less frequently against contactin-associated protein-like 2 (Caspr2) [2-5]. We describe the first case of a patient with eyelid tremor associated with anti-Caspr2 antibody. 


\section{Case Report}

A 63-year-old man was admitted to the hospital because he had become mute and akinetic. No specific family or personal history was noted. Starting about 1 year before admission his daily activities progressively decreased, and he confined himself to his house. One month before admission he was not eating adequately, and 3 weeks later he was completely bedridden and refused to eat. On admission, the patient's height was $160 \mathrm{~cm}$ and his body weight was $51.8 \mathrm{~kg}\left(-8 \%\right.$ of the ideal weight). The body temperature was $36.8^{\circ} \mathrm{C}$, and his consciousness was E1, V1, and M1 on the Glasgow Coma Scale (GCS). With his eyes closed, he had a 1-2-Hz eyelid tremor without nystagmus (online suppl. video 1; for all online suppl. material, see www.karger.com/doi/10.1159/000366408). He had parkinsonism, including a masked face and left-arm rigidity. Deep tendon reflexes were normal with an equivocal response on plantar-reflex testing. All extremities were amyotrophic, possibly because of disuse syndrome. Respiratory failure was not apparent. The patient's disturbed consciousness prevented testing the sensory or cerebellar systems. Constipation and urinary retention were present but other autonomic regulations, including those of the cardiovascular systems or sweat glands, were not apparently affected. His blood contained an increased WBC count $(18,700 / \mu \mathrm{l})$ with normal counts of RBC and platelets. Blood chemistry showed an increased CRP level (16.8 mg/dl, normal 0-0.3). The patient's urine contained high levels of occult blood and protein. These findings were consistent with bladder infection secondary to urine retention and were resolved by drip infusion of an antibiotic $(2 \mathrm{~g} /$ day ceftriaxone sodium for 3 days). Thyroid function was normal. Serum autoantibody against thyroid peroxidase, TSH (thyroid stimulating hormone) receptor, SSA (Sjögren syndrome type A antigen), SSB (Sjögren syndrome type B antigen), GAD (glutamic acid decarboxylase), Hu, Yo, $\mathrm{Ri}, \mathrm{Ma}, \mathrm{Ta}, \mathrm{CV} 2$ (Crossveinless-2), amphisin, or VGCC (voltage-gated calcium channel) was negative. Cerebrospinal fluid (CSF) analysis revealed a normal cell count (3 cells/ $\mu \mathrm{l})$ and a normal protein level $(27 \mathrm{mg} / \mathrm{dl})$ without oligoclonal IgG band. MRI only showed mild diffuse atrophy and punctate increased signals of the frontal white matter (fig. 1). Electroencephalogram (EEG) showed 7-8-Hz background waves without apparent epileptic discharges.

Further investigation, including the examination of autoantibodies against neuronal cell surface antigens, revealed that anti-Caspr2 antibody was positive in CSF [4]. Since antiCaspr2 antibody is occasionally associated with thymoma, we performed whole-body PET and CT, the result of which failed to identify tumors.

After six cycles of methylprednisolone pulse therapy ( $1 \mathrm{~g}$ for 3 days) and two cycles of plasmapheresis (7 times/cycle), the patient's consciousness improved to E3, V1, and M5 on the GCS. He did not follow verbal orders, but could walk without a cane when manually guided. However, he did not eat voluntarily, which resulted in nasogastric tube feeding. Eyelid tremor was not obvious, but frequent blinking was observed (see online suppl. video 2). The rigidity of the left arm resolved. Anti-Caspr2 antibody became negative in CSF. Brain MRI did not change (data not shown). EEG showed $8-9-\mathrm{Hz}$ background waves with occasional appearance of diffuse $7-\mathrm{Hz}$ waves. The patient was transferred to a rehabilitation hospital. One and a half years after having been discharged from our hospital, his medical condition remained essentially unchanged.

\section{Discussion}

We describe the first case of a patient who had eyelid tremor with anti-Caspr2 antibodyrelated encephalitis. Recently, the clinical spectrum of anti-Caspr2 antibody-related 
Ueno et al.: Eyelid Tremor in a Patient with Anti-Caspr2 Antibody-Related Encephalitis

encephalitis has been broadened considerably from limbic encephalitis; $10 \%$ of patients with idiopathic cerebellar ataxia were positive for this antibody [6]. Moreover, a case report described a patient with ataxia, myoclonus, and dyskinesia in addition to symptoms of limbic encephalitis [7]. Despite such a broadened clinical spectrum, a recent large clinicoserologic study demonstrated that extrapyramidal signs, including tremor, parkinsonism, and chorea, were not common in this disease as they were observed in only 1 patient (about 3\%) [8]. Nonetheless, the eyelid tremor, masked face, and rigidity found in our patient may support the extrapyramidal involvement, which may be further supported by a very recent case report describing hemichorea in a patient with anti-Caspr2 antibody [9]. Since clinical details of this disease have been reported infrequently, their accumulation might identify susceptible central nervous system regions and help the correct diagnosis.

In conclusion, we reported on a patient with anti-Caspr2 antibody who had rare and common symptoms and partially responded to immunotherapy when the antibody disappeared. Notably, the tremor frequency of eyelid tremor in our patient $(1-2 \mathrm{~Hz})$ was lower than that in previously reported patients $(5-7 \mathrm{~Hz})$ [1]. Whether this discrepancy can be attributed to the antibody awaits future studies.

\section{Acknowledgment}

We thank Dr. Dalmau of the University of Pennsylvania for the measurement of anti-Caspr2 antibody.

\section{References}

1 Jungehulsing GJ, Ploner CJ: Eyelid tremor in a patient with a unilateral paramedian thalamic lesion. J Neurol Neurosurg Psychiatry 2003;74:356-358.

-2 Lai M, Huijbers MG, Lancaster E, Graus F, Bataller L, Balice-Gordon R, Cowell JK, Dalmau J: Investigation of LGI1 as the antigen in limbic encephalitis previously attributed to potassium channels: a case series. Lancet Neurol 2010;9:776-785.

-3 Vincent A, Irani SR: Caspr2 antibodies in patients with thymomas. J Thorac Oncol 2010;5:S277-S280.

$\checkmark 4$ Lancaster E, Huijbers MG, Bar V, Boronat A, Wong A, Martinez-Hernandez E, Wilson C, Jacobs D, Lai M, Walker RW, Graus F, Bataller L, Illa I, Markx S, Strauss KA, Peles E, Scherer SS, Dalmau J: Investigations of caspr2, an autoantigen of encephalitis and neuromyotonia. Ann Neurol 2011;69:303-311.

-5 Irani SR, Pettingill P, Kleopa KA, Schiza N, Waters P, Mazia C, Zuliani L, Watanabe O, Lang B, Buckley C, Vincent A: Morvan syndrome: clinical and serological observations in 29 cases. Ann Neurol 2012;72:241255.

6 Becker EB, Zuliani L, Pettingill R, Lang B, Waters P, Dulneva A, Sobott F, Wardle M, Graus F, Bataller L, Robertson NP, Vincent A: Contactin-associated protein-2 antibodies in non-paraneoplastic cerebellar ataxia. J Neurol Neurosurg Psychiatry 2012;83:437-440.

7 Balint B, Regula JU, Jarius S, Wildemann B: Caspr2 antibodies in limbic encephalitis with cerebellar ataxia, dyskinesias and myoclonus. J Neurol Sci 2013;327:73-74.

-8 Klein CJ, Lennon VA, Aston PA, McKeon A, O’Toole O, Quek A, Pittock SJ: Insights from LGI1 and CASPR2 potassium channel complex autoantibody subtyping. JAMA Neurol 2013;70:229-234.

-9 Vynogradova I, Savitski V, Heckmann JG: Hemichorea associated with CASPR2 antibody. Tremor Other Hyperkinet Mov (NY) 2014;4:239. 
Ueno et al.: Eyelid Tremor in a Patient with Anti-Caspr2 Antibody-Related Encephalitis

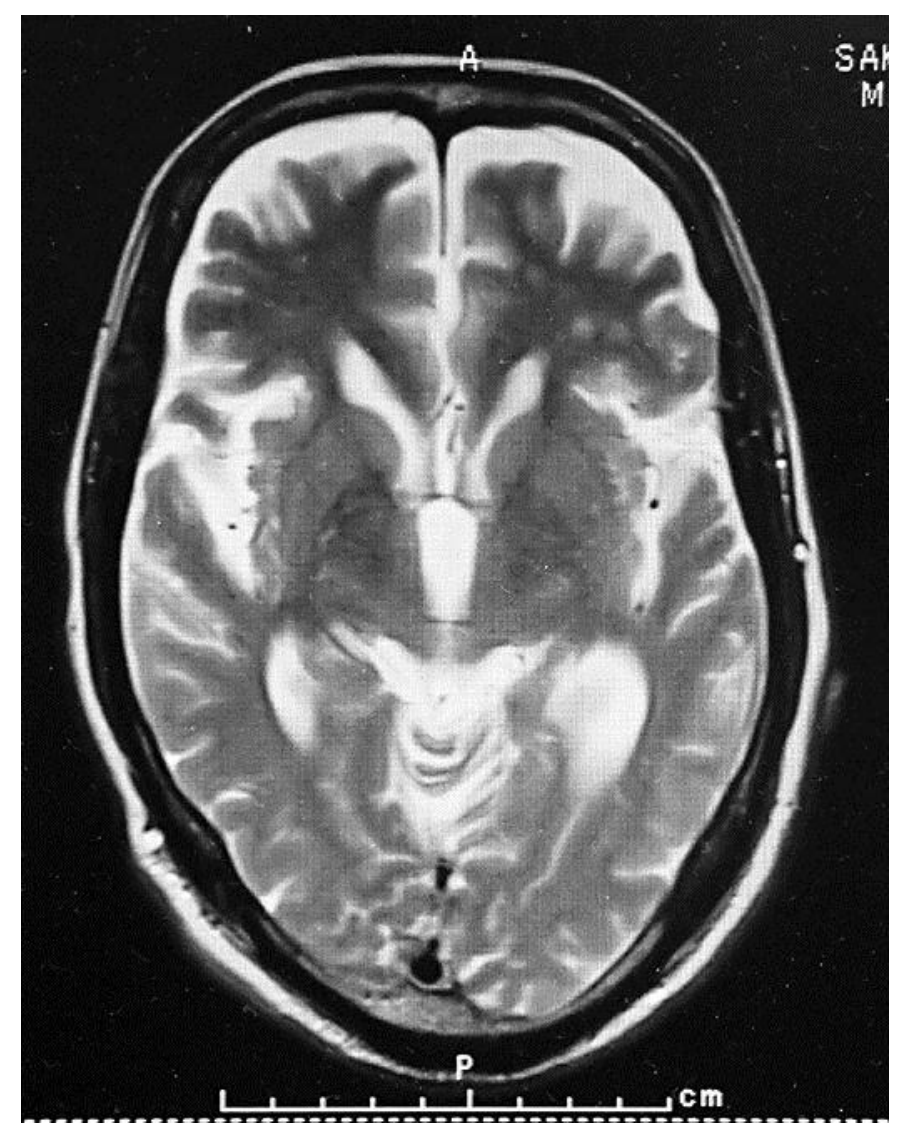

Fig. 1. Brain MRI [Siemens MAGNETOM Symphony 1.5T, T2WI (TR/TE = 1,300/69 ms)] showing mild diffuse atrophy and punctate increased signals of the frontal white matter. 